\title{
A PROBLEM SOLVED
}

\author{
ICCA Communication \\ by J. ten Have
}

On the occasion of the Fifth World Microcomputer-Chess Championship, a chess problem was published in the ICCA Journal (Vol. 8, No. 3, p. 181). The organizing committee had asked the Dutch chess-problem composer Jac. Haring to supply a problem that could be assumed to cause extra difficulties for a computer program. The idea was that the shortcomings of chess computers should be revealed to owners and also to their creators. Mr. Jac. Haring composed three retrograde problems, reproduced in Diagram 1 below.

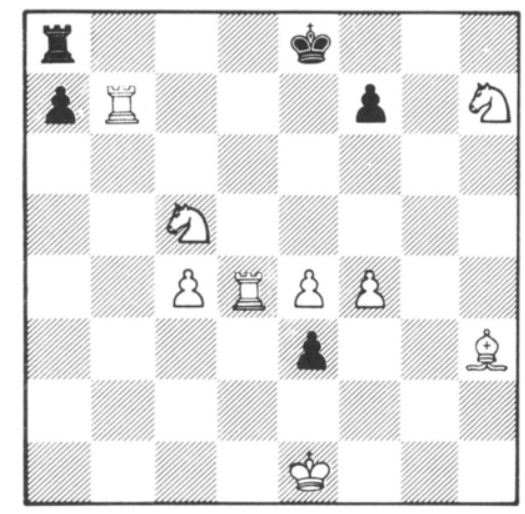

The three problems (all mate-in-two) are:

A. The diagrammed position.

B. The diagrammed position without Pawn e4.

C. The diagrammed position without Pawn f4, but with a Pawn on a6 instead.

\section{DIAGRAM 1}

White to move;

Mate in two.

The solutions are:
A. 1. Nd7! (1. ... 0-0-0 is not allowed since Black's last move must have been either a King or a Rook move.)
B. 1. Ne4! (1. Nd7? 0-0-0, because Black's last move may have been e4-e3.)
C. 1. Nd7! 0-0-0 2. Nb6 mate (Black's last move may have been f4xe3.)

The winners are:
First prize:
G. Visser, Churchilllaan 45:4, 1078 DE Amsterdam, The Netherlands.
Second prize:
G. Maan, Staniasingel 3, 9062 GL Oenkerk, The Netherlands
Third to Twelfth prizes: R. Bakker (Sittard, The Netherlands) H. ten Braak (Amsterdam, The Netherlands) J.J. Burbach (Hilversum, The Netherlands) W. Festze (Nürnberg, Western Ger- many) C.A. van Gunst (Sittard, The Netherlands) B. Jongsma (Groningen, The Netherlands) G.J. Naayer (Louvier, France) C.A. Nuzzo (Zaragoza, Spain) W. Priepke (Filderstadt, Western Ger- many) A. Schokler (Groningen, The Netherlands) 
The number of solutions submitted: 145 (of which 75 were correct).

As an extra for our readers, Jac. Haring also gave us (Vol. 8, No.3, p.181) the problem reproduced in Diagram 2.

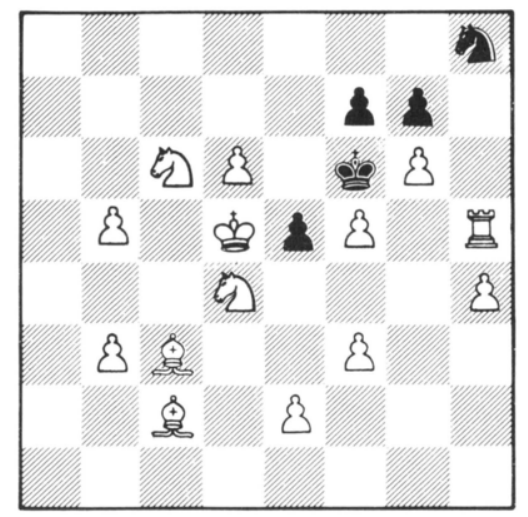

\section{DIAGRAM 2}

White to move;

Mate in two.

It is easy to see that Black's last move must have been e7-e5, allowing White to capture the Pawn en passant. Therefore the solution reads 1. f5xe6 e.p. Most present computer programs cannot reason backwards; thus they have difficulties with such a problem.

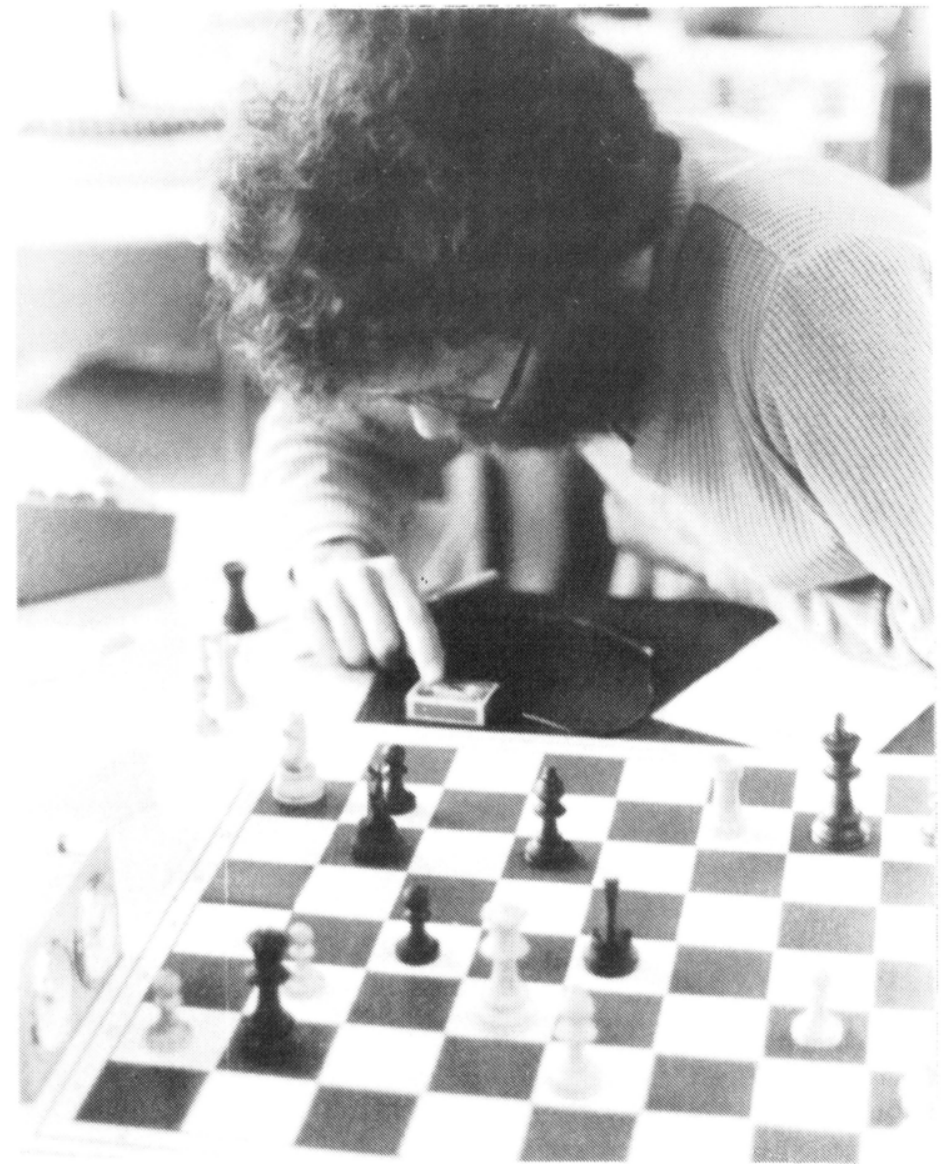

Photo by K.E. Börjars

THE MATCHLESS MATCHBOX

Harm Geert Muller, its father, entering the opponent's move into the smallest competitor ever. 